\title{
ResearchArticle
}

\section{Correlation study between yield components in WA based rice hybrids}

\author{
Ashish Goswami and Vishal Seth
}

\section{SUMMARY}

Twenty hybrids along with three cytoplasmic sterile lines (IR 58025A, IR 98897, IR 56256A, DRR 9A and DRR10A) and eighteen pollen parents were studied for character association for yield and its components. Correlation studies in conjunction with heterosis estimates gives some idea as to the relative importance of each of the components to final grain yield. It also gives some idea about the changed relationship between character pairs in parents as well as in hybrids, although it is a established fact that nature and magnitude of associations would vary with the composition of the material. In present study, simple correlation co-efficients were estimated at both phenotypic and genotypic levels in parents as well as hybrids, separately. It was observed that the magnitude of association varied in hybrids and parents. In hybrids the yield was primarily influenced by 100 grain weight, effective tillers per plant and number of fertile grains per panicle. In case of parents grain yield per plant found to be significantly and positively correlated with days to $50 \%$ flowering, panicle length, effective tillers per plant and number of fertile grains per panicle. Characters like effective tiller number per plant and fertile grains per panicle were significantly and positively correlated with each other as well as with grain yield per plant.

Key Words : Rice, Hybrids, Correlation, Character association

How to cite this article : Goswami, Ashish and Seth, Vishal (2018). Correlation study between yield components in WA based rice hybrids. Internat. J. Plant Sci., 13 (1): 127-130, DOI: 10.15740/HAS/IJPS/13.1/127-130.

Article chronicle : Received : 27.10.2017; Revised : 29.11.2017; Accepted : 13.12.2017

\footnotetext{
$\longrightarrow$ MEMBERS OF THE RESEARCH FORUM

Author to be contacted :

Ashish Goswami, Department of Genetics and Plant Breeding, Udai

Pratap Autonomous College, Varanasi (U.P.) India

Email : ashishgoswamiupc2013@gmail.com

Address of the Co-authors:

Vishal Seth, Department of Genetics and Plant Breeding, Udai Pratap Autonomous College, Varanasi (U.P.) India
} 